\section{Community-Based Therapy for Multidrug-Resistant Tuberculosis in Lima, Peru}

\author{
Carole Mitnick, Sc.D., Jaime Bayona, M.D., M.P.H., Eda Palacios, R.N., \\ Sonya Shin, M.D., Jennifer Furin, M.D., Ph.D., Felix Alcántara, M.D., \\ Epifanio Sánchez, M.D., Madeleny Sarria, R.N., Mercedes Becerra, Sc.D., \\ Mary C. Smith Fawzi, Sc.D., Saidi Kapiga, M.D., Sc.D., Donna Neuberg, Sc.D., \\ James H. Maguire, M.D., Jim Yong Kim, M.D., Ph.D., and Paul Farmer, M.D., Ph.D.
}

\section{ABSTRACT}

\section{BACK GROU N D}

Despite the prevalence of multidrug-resistant tuberculosis in nearly all low-income countries surveyed, effective therapy has been deemed too expensive and considered not to be feasible outside referral centers. We evaluated the results of communitybased therapy for multidrug-resistant tuberculosis in a poor section of Lima, Peru.

\section{METHODS}

We describe the first 75 patients to receive ambulatory treatment with individualized regimens for chronic multidrug-resistant tuberculosis in northern Lima. We conducted a retrospective review of the charts of all patients enrolled in the program between August 1, 1996, and February 1, 1999, and identified predictors of poor outcomes.

\section{RESULTS}

The infecting strains of Mycobacterium tuberculosis were resistant to a median of six drugs. Among the 66 patients who completed four or more months of therapy, 83 percent (55) were probably cured at the completion of treatment. Five of these 66 patients (8 percent) died while receiving therapy. Only one patient continued to have positive cultures after six months of treatment. All patients in whom treatment failed or who died had extensive bilateral pulmonary disease. In a multiple Cox proportional-hazards regression model, the predictors of the time to treatment failure or death were a low hematocrit (hazard ratio, 4.09; 95 percent confidence interval, 1.35 to 12.36) and a low body-mass index (hazard ratio, 3.23; 95 percent confidence interval, 0.90 to 11.53). Inclusion of pyrazinamide and ethambutol in the regimen (when susceptibility was confirmed) was associated with a favorable outcome (hazard ratio for treatment failure or death, 0.30 ; 95 percent confidence interval, 0.11 to 0.83 ).

\section{CONCLUSIONS}

Community-based outpatient treatment of multidrug-resistant tuberculosis can yield high cure rates even in resource-poor settings. Early initiation of appropriate therapy can preserve susceptibility to first-line drugs and improve treatment outcomes.
From the Program in Infectious Disease and Social Change, Harvard Medical School, Boston (C.M., J.B., S.S., J.F., M.B., M.C.S.F., J.Y.K., P.F.); the Harvard School of Public Health, Boston (C.M., S.K., D.N., J.H.M.); Partners In Health, Boston (C.M., J.B., S.S., J.F., M.B., M.C.S.F., J.Y.K., P.F.); Socios En Salud, Carabayllo, Lima, Peru (J.B., E.P., F.A.); the Division of Infectious Diseases, Brigham and Women's Hospital, Boston (S.S., J.H.M., P.F.); Hospital Sergio E. Bernales, Carabayllo, Lima, Peru (E.S.); and Servicios Basicos de Salud, Comas, Lima, Peru (M.S.). Address reprint requests to Dr. Mitnick at the Program in Infectious Disease and Social Change, Department of Social Medicine, Harvard Medical School, 643 Huntington Ave., 4th Fl., Boston, MA 02115, or at carole_mitnick@ hms.harvard.edu.

N EnglJ Med 2003;348:119-28. Copyright $\odot 2003$ Massachusetts Medical Societv. 
I N PERU, MULTIDRUG-RESISTANT TUBERculosis, defined as disease caused by strains of Mycobacterium tuberculosis that are resistant to at least isoniazid and rifampin, is responsible for about 3 percent $t^{1,2}$ of cases among patients not previously treated for tuberculosis and about 15 percent of cases among those previously treated. It has frequently been suggested that the comprehensive "DOTS" strategy - which involves giving a short course of directly observed multidrug treatment, as well as requiring government commitment, case detection by smear microscopy, a regular supply of antituberculosis drugs, and standardized recording and reporting - can eliminate multidrug-resistant tuberculosis. ${ }^{3-5}$ However, the short-course chemotherapy on which DOTS is based usually fails to cure multidrug-resistant tuberculosis..$^{6-8}$ Rates of cure of multidrug-resistant tuberculosis with standardized short-course chemotherapy range from 5 percent $^{9}$ to 60 percent. $^{10}$

Therapy for multidrug-resistant tuberculosis has been virtually nonexistent in poor countries. It has been argued that drug-susceptibility testing and second-line drugs are not cost effective in these countries because of limited resources and that intensive clinical management is impossible because of lack of infrastructure. ${ }^{3,11,12}$ There are few treatment models, and the reported rates of success of treatment of multidrug-resistant tuberculosis in middle-income countries and regions ranged in recent reports from less than 60 percent in Indonesia and Taiwan ${ }^{13,14}$ to just over 80 percent in Hong Kong, Korea, and Turkey. ${ }^{15-17}$ In these studies, treatment of multidrug-resistant tuberculosis was costly and was provided in referral hospitals. The few studies of the treatment of multidrug-resistant tuberculosis in outpatients all found successful outcomes in less than half of cases. ${ }^{18-20}$

Without treatment, multidrug-resistant strains can spread rapidly within vulnerable populations. ${ }^{21-23}$ Because standardized short-course chemotherapy for multidrug-resistant tuberculosis has been associated with unacceptably high rates of failure and relapse, ${ }^{6,10,24}$ new approaches to treatment in poor countries are needed. ${ }^{25-27}$ We conducted a community-based project for the treatment of multidrug-resistant tuberculosis in a resource-poor setting. This DOTS-Plus project - which entailed the addition of second-line drugs, monitoring by sputum culture, drug-susceptibility testing, and directly observed individualized therapy ${ }^{28}$ to the well- established Peruvian DOTS program - treated a cohort of patients with long-standing disease due to highly resistant strains of $M$. tuberculosis. ${ }^{29,30} \mathrm{We}$ identified risk factors associated with poor outcomes and predictors of the time to death.

METHODS

\section{STUDY PATIENTS}

Between August 1, 1996, and November 30, 1998, 731 patients were referred for evaluation for multidrug-resistant tuberculosis by Socios En Salud, a nongovernmental organization working in northern Lima, Peru, in collaboration with the Peruvian Ministry of Health and academic and nongovernmental organizations based in the United States. Seventy-five (10 percent) met the following criteria for inclusion in the study: beginning of supervised, individualized treatment for multidrug-resistant tuberculosis before February 1, 1999; residence in the government-approved catchment area in northern Lima (Carabayllo, Comas, and Independencia districts); referral by a collaborating health center after the failure of at least one course of directly observed, standardized short-course chemotherapy; laboratory-documented multidrug-resistant tuberculosis; survival until the results of drug-susceptibility testing became available; and provision of written informed consent. All 75 patients who began therapy during this period are included in this report; high-grade drug resistance, gravity of disease, and the presence of coexisting conditions were not indications for exclusion. Most patients referred did not live in the catchment area.

\section{BACTERIOLOGIC STUDIES \\ AND DRUG-SUSCEPTIBILITY TESTING}

Sputum samples were collected for smear microscopy and culture at base line and monthly thereafter. The samples were processed and read according to international standards ${ }^{31}$ at Sergio E. Bernales Hospital in Lima. At base line, isolates of M. tuberculosis were tested for susceptibility to the following drugs: isoniazid (concentrations, $0.2,1$, and $5 \mu \mathrm{g}$ per milliliter), rifampin ( $1 \mu \mathrm{g}$ per milliliter), ethambutol ( $5 \mu$ g per milliliter), pyrazinamide $(100 \mu \mathrm{g}$ per milliliter), streptomycin ( 2 and $10 \mu \mathrm{g}$ per milliliter), kanamycin ( $5 \mu \mathrm{g}$ per milliliter), capreomycin $(10 \mu \mathrm{g}$ per milliliter), ethionamide ( $5 \mu \mathrm{g}$ per milliliter), cycloserine (30 $\mu$ g per milliliter), and ciprofloxacin ( $2 \mu$ g per milliliter). Testing was performed by staff 
members of the Massachusetts State Laboratory Institute, using the proportion method ${ }^{32}$ on $7 \mathrm{H} 10$ agar plates and, for pyrazinamide, the BACTEC ${ }^{33}$ method. Highly resistant isolates were tested on $7 \mathrm{H} 9$ agar plates for susceptibility to amikacin $(2,4$, and $8 \mu \mathrm{g}$ per milliliter), rifabutin $(0.12,0.5$, and $2 \mu \mathrm{g}$ per milliliter), and clarithromycin (2, 8, and $32 \mu \mathrm{g}$ per milliliter) at the National Jewish Medical and Research Center in Denver.

TREATMENT AND MONITORING OF ADVERSE EVENTS

While the results of susceptibility testing were pending, most patients were treated empirically under direct observation with regimens containing at least five drugs to which their strains were deemed likely to be sensitive on the basis of previous regimens used. The definitive regimens, containing a minimum of five drugs and lasting at least 18 months, were determined on the basis of the results of drug susceptibility tests, which were available a mean $( \pm S D)$ of $62.6 \pm 32.9$ days after sputum collection. First-line drugs were used preferentially even in cases in which repeated test results were inconsistent, provided that susceptibility had been documented at least once. A parenteral agent was administered for at least six months after culture conversion. ${ }^{34}$ Treatment was terminated after 12 or more consecutive negative cultures had been recorded. Sputum samples continued to be collected and cultured at least annually after the completion of treatment. Patients received limited nutritional, financial, and social support through Socios En Salud. ${ }^{35}$

Treatment was given on an outpatient basis. Treatment and surveillance for adverse events were managed by a team of specially trained community health workers, nurses, and physicians under the auspices of Socios En Salud. ${ }^{29,30}$ Each patient underwent complete clinical - including neurologic, psychiatric, and audiometric - evaluations before enrollment. Base-line laboratory analyses included a complete blood count, measurement of blood urea nitrogen and serum creatinine, tests of hepatic function (measurement of serum aminotransferases, bilirubin, and alkaline phosphatase), enzymelinked immunosorbent assay for the human immunodeficiency virus (HIV), and a Venereal Disease Research Laboratory test at base line. Monitoring of renal and hepatic function was performed regularly during therapy; other laboratory tests were performed as indicated, on the basis of symptoms.

\section{DEFINITIONS OF OUTCOME}

Probable cure was defined by at least 12 months of consecutive negative cultures during therapy; a single intervening positive culture with fewer than 10 colonies was allowed. Treatment failure was defined by the presence of a positive culture after six months of treatment. Withdrawal from therapy was defined by one or more months of missed therapy during the first year, and two or more months missed during the second year. Death was defined as death from any cause during therapy or follow-up. Relapse was defined by two or more positive cultures after the completion of treatment among patients whose treatment outcome was probable cure.

\section{COLLECTION OF DATA}

Patients' characteristics and risk factors at base line (drawn from clinical records with the use of a structured instrument) included the following: extent of pulmonary parenchymal damage; number of previous treatments; low body-mass index (the weight in kilograms divided by the square of the height in meters), defined as less than 18.5 for women and less than 20 for men ${ }^{36}$; anemia, defined as a hematocrit of less than 30 percent in women or less than 36 percent in men ${ }^{37}$; the number of antituberculosis agents to which the infecting strain was resistant; the number of drugs in the regimen; age; sex; household size; history of homelessness, substance abuse, or institutionalization; medical history and coexisting conditions; respiratory difficulty, observed as tachypnea at rest (more than 26 breaths per minute), ${ }^{38}$ dyspnea at rest or on exertion, or use of accessory muscles; and the time elapsed since the first diagnosis of tuberculosis and multidrug-resistant tuberculosis.

\section{STATISTICAL ANALYSIS}

Statistical analyses were performed to determine the associations between risk factors and a poor outcome (treatment failure or death) during therapy and the follow-up period, through August 31, 2002.

Clinically relevant risk factors were analyzed with the use of Kaplan-Meier estimates and Cox proportional-hazards models to generate estimates of the associations with the time to death or treatment failure. Confounding by demographic characteristics, previous treatment history, and resistance to first-line drugs was assessed by multiple Cox proportional-hazards models. Plots of the natural logarithm of the negative of the natural logarithm of 
the survival curves for all levels of primary predictors were consistent with the assumption of proportionality. ${ }^{39}$ Data on patients who withdrew from therapy were censored at the time of withdrawal, since their risk of a poor clinical outcome could no longer be assessed. ${ }^{40}$

Data were entered into Access97 (Microsoft). Data were missing for some patients for some risk factors; missing values for body-mass index and hematocrit were imputed as the sex-specific medians. SAS software (version 8.1) was used for all analyses. All reported P values are two-sided.

\section{RESULTS}

BASE-LINE DEMOGRAPHIC

AND CLINICAL CHARACTERISTICS

The patients were young, and most were single (Table 1), with nearly equal numbers of men and women. The household size was generally large, and often two or more patients came from a single household. More than half the patients had prior or current medical illness; four had concurrent extrapulmonary tuberculosis. One of 65 patients tested had HIV infection. A low hematocrit was recorded in 12 patients (18 percent). Nearly half the patients had an elevated resting respiratory rate, a low body-mass index, or both. Bilateral cavitary parenchymal disease was evident in 47 base-line chest radiographs ( 63 percent). The patients had received treatment with a median of 3 prior antituberculosis regimens (range, 0 to 8 ) during the nearly four years between the diagnosis of tuberculosis and the initiation of the individualized regimens described here. The patients had been previously exposed to a median of 7 antituberculosis drugs (range, 0 to 10) for at least one month each. The infecting strains of M. tuberculosis were resistant to a median of 6 drugs (range, 2 to 12 ).

\section{OUTCOMES}

The 75 patients received treatment with 58 different regimens (Fig. 1), containing a median of six drugs (range, five to nine) (Table 2) and lasting a median of 23 months (range, 0.4 to 35.9). The records of 60 patients were reviewed systematically for adverse events; 44 patients ( 73 percent) had such events, and all events were managed without physician-directed discontinuation of therapy. ${ }^{41}$

Sixty-six patients completed four or more months of therapy; conversion was evident in smears and cultures in a median of just over one month. Of these
66 patients, 55 ( 83 percent) had probable cures at the completion of therapy, 5 patients (8 percent) withdrew from therapy, therapy failed in 1 patient, and 5 patients ( 8 percent) died while receiving therapy, after having completed more than four months of therapy.

Patients were followed for a median of 40 months (range, 7 to 66) after therapy. During therapy and follow-up, 18 poor clinical outcomes occurred: 17 deaths and 1 failure of therapy. Autopsies were not performed; the causes of death, as suggested by the clinical history, are shown in Table 3.

\section{PREDICTORS OF A POOR CLINICAL OUTCOME}

In univariate analyses, a low hematocrit was found to predict a poor outcome throughout therapy and follow-up: after four months of therapy, only four patients with a normal base-line hematocrit value (6 percent) had died, whereas five patients with a low hematocrit ( 42 percent) had died $(\mathrm{P}<0.001$ by the generalized Wilcoxon test). Low base-line bodymass index was also predictive of earlier death: at four months, only one patient with normal baseline body-mass index ( 2 percent) and eight patients with low body-mass index ( 25 percent) had died $(\mathrm{P}<0.001$ by the generalized Wilcoxon test).

In the final multiple Cox proportional-hazards regression model, a low hematocrit $(\mathrm{P}=0.01$ by the Wald $\chi^{2}$ test) and resistance to pyrazinamide or ethambutol ( $\mathrm{P}=0.02$ by the Wald $\chi^{2}$ test) were significantly associated with the time to a poor outcome (Table 4). Although low body-mass index was of borderline statistical significance in this model ( $\mathrm{P}=0.07$ by the Wald $\chi^{2}$ test), it confounded the effect of a low hematocrit, lowering the effect estimate by more than 30 percent. After adjustment for low body-mass index and low hematocrit, nulliparous women were at greater risk for a shorter time to a poor outcome than other women $(\mathrm{P}=0.01$ by the Wald $\chi^{2}$ test).

\section{DISCUSSION}

Large-scale, standardized surveys have revealed the presence of patients with multidrug-resistant pulmonary tuberculosis in virtually every country studied, yet to date, specific therapy for this disease has been restricted to high- and middle-income countries where care is usually delivered within specialized referral centers. This project in Peru yielded more probable cures than expected in patients whose prognosis was poor because of chronic, 


\begin{tabular}{|c|c|c|}
\hline Characteristic: & No. of Patients (\%) & Median (Range) \\
\hline \multicolumn{3}{|l|}{ Sex } \\
\hline Male & $37(49)$ & \\
\hline Female & $38(51)$ & \\
\hline Age (yr) & & $26.8(11.8-65.1)$ \\
\hline Household size (no. of members) & & $7(2-20)$ \\
\hline \multicolumn{3}{|l|}{ Marital status } \\
\hline Unmarried (single, widowed, separated, or divorced) & $47(66)$ & \\
\hline Married & $24(34)$ & \\
\hline Parity & & $0(0-9)$ \\
\hline 0 live births & $23(61)$ & \\
\hline$\geq 1$ live births & $15(39)$ & \\
\hline Hematocrit (\%) & & $36.5(21-51)$ \\
\hline Men & & $41(21-48)$ \\
\hline Women & & $34(24-51)$ \\
\hline Men with hematocrit <36\% & $7(23)$ & \\
\hline Women with hematocrit $<30 \%$ & $5(14)$ & \\
\hline \multicolumn{3}{|l|}{ Observed respiratory difficulty $\dagger$} \\
\hline Any & $32(49)$ & \\
\hline None & $33(51)$ & \\
\hline Resting respiratory rate & & $25(15-40)$ \\
\hline$>26$ breaths $/ \mathrm{min}$ & $13(45)$ & \\
\hline$\leq 26$ breaths $/ \mathrm{min}$ & $16(55)$ & \\
\hline Body-mass index & & $19.9(12.4-29.8)$ \\
\hline Men & & $20.6(13.1-29.8)$ \\
\hline Women & & $19.0(12.4-25.2)$ \\
\hline Men with body-mass index $<20$ & $15(41)$ & \\
\hline Women with body-mass index $<18.5$ & $17(45)$ & \\
\hline \multicolumn{3}{|l|}{ Previous or current coexisting condition $\Varangle$} \\
\hline Any & $40(53)$ & \\
\hline None & $35(47)$ & \\
\hline $\begin{array}{l}\text { History of homelessness, imprisonment, other institutionalization, or addiction } \\
\text { to drugs or alcohol }\end{array}$ & $17(23)$ & \\
\hline Months from first diagnosis of tuberculosis to individualized treatment regimen & & $44.2(2.1-383.4)$ \\
\hline $\begin{array}{l}\text { Months from first diagnosis of multidrug-resistant tuberculosis to individual- } \\
\text { ized treatment regimen }\end{array}$ & & $8.1(0.2-103.2)$ \\
\hline \multicolumn{3}{|l|}{ No. of drugs to which M. tuberculosis strain was resistant at initiation of treatment $₫$} \\
\hline All drugs & & $6(2-12)$ \\
\hline First-line drugs & & $5(2-5)$ \\
\hline Second-line drugs & & $1(0-7)$ \\
\hline Parenteral drugs & & $1(0-4)$ \\
\hline
\end{tabular}

* Data on some of the characteristics were missing for some patients. Data on household size were available for 69 patients; on marital status, for 71; on parity, for the 38 women; on hematocrit, for 68 patients; on respiratory difficulty, for 65 ; on respiratory rate, for 29; and on body-mass index, for 69 .

$\dagger$ Observed respiratory difficulty was defined as dyspnea, use of accessory muscles, or elevated resting respiratory rate.

$\uparrow$ Previous or current coexisting conditions included psychiatric illness (28 patients), hepatitis (3 patients), human immunodeficiency virus infection (1 patient), hypothyroidism (1 patient), diabetes (1 patient), epilepsy (1 patient), malnutrition (15 patients), anemia (12 patients), gastritis (10 patients), and aortic stenosis (1 patient).

$\int$ The drugs tested were isoniazid, pyrazinamide, rifampin, ethambutol, streptomycin, kanamycin, capreomycin, ciprofloxacin, ethionamide, and cycloserine; when clinically indicated, amikacin, rifabutin, and clarithromycin were also tested. The first-line drugs were isoniazid, rifampin, pyrazinamide, ethambutol, and streptomycin. The second-line drugs were kanamycin, capreomycin, ciprofloxacin (or other fluoroquinolones), ethionamide, cycloserine, amikacin, rifabutin, and clarithromycin. The parenteral drugs were streptomycin, kanamycin, capreomycin, and amikacin. 


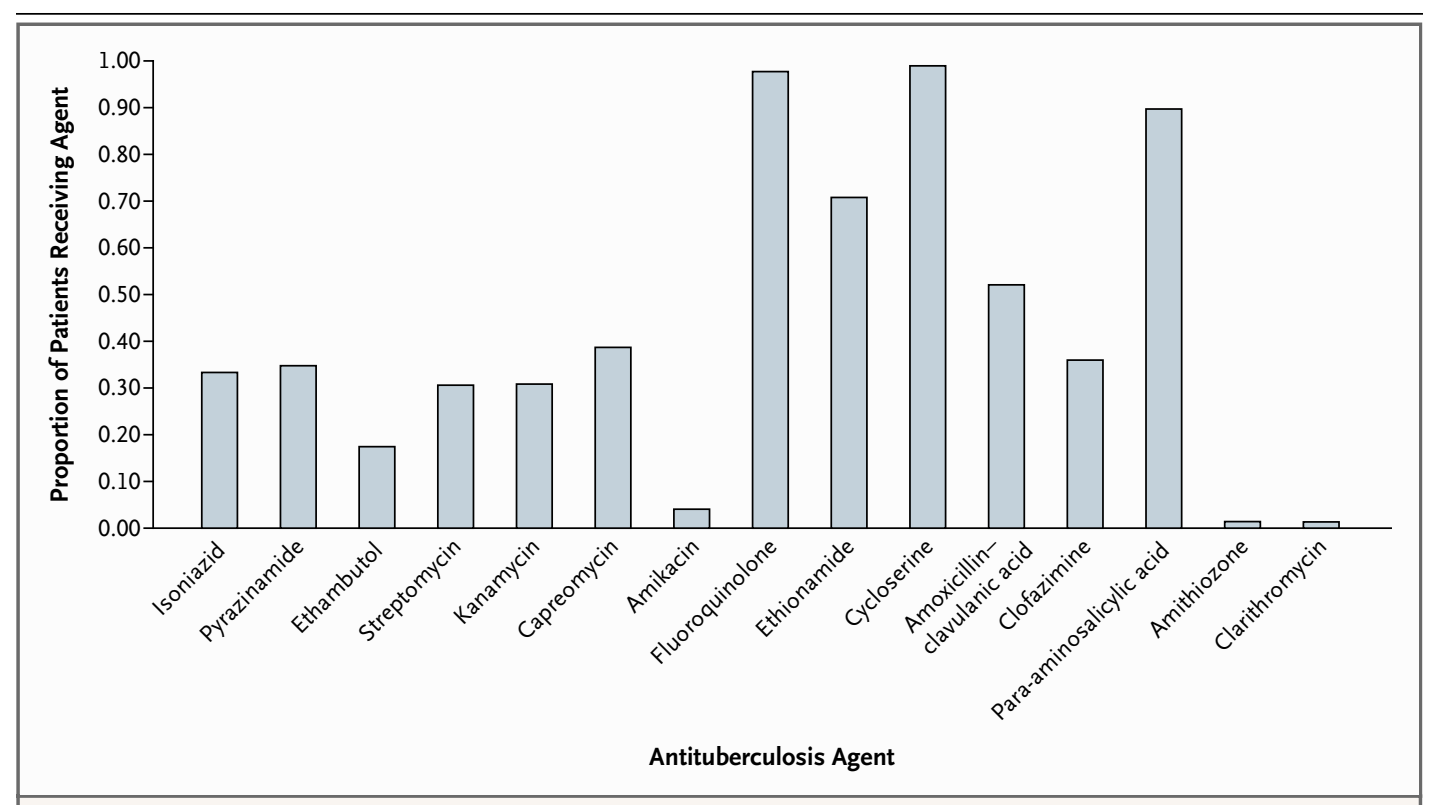

Figure 1. Frequency Distribution of Antituberculosis Agents Received by the 75 Patients as Part of Individualized Treatment Regimens.

All patients were infected with strains that were resistant to at least low-dose isoniazid (critical concentration, $0.2 \mu \mathrm{g}$ per milliliter) and rifampin. High-dose isoniazid ( $900 \mathrm{mg}$ twice weekly) was given to patients whose infecting strains had in vitro susceptibility to high-dose isoniazid (critical concentration, $5.0 \mu \mathrm{g}$ per milliliter). The fluoroquinolones used were ciprofloxacin and ofloxacin.

\begin{tabular}{|c|c|c|}
\hline Table 2. Characteristics of Treatment Regimens.* & & \\
\hline Characteristic & No. (\%) & $\begin{array}{l}\text { Median } \\
\text { (Range) }\end{array}$ \\
\hline $\begin{array}{l}\text { No. of drugs per patient in individualized treatment } \\
\text { regimen }\end{array}$ & & $6(5-9)$ \\
\hline First-line drugs & & $1(0-4)$ \\
\hline Second-line drugs & & $5(2-7)$ \\
\hline Parenteral drugs & & $1(1-2)$ \\
\hline \multicolumn{3}{|l|}{$\begin{array}{l}\text { Receipt of regimen containing ethambutol } \\
\text { or pyrazinamide }\end{array}$} \\
\hline $\begin{array}{l}\text { Regimen containing ethambutol } \\
\text { and pyrazinamide }\end{array}$ & $6(8)$ & \\
\hline Regimen containing ethambutol only & $7(9)$ & \\
\hline Regimen containing pyrazinamide only & $20(27)$ & \\
\hline Regimen containing neither drug & $42(56)$ & \\
\hline \multicolumn{3}{|l|}{ Time to conversion - days } \\
\hline Smear & & $38(14-264)$ \\
\hline Culture & & $35(23-181)$ \\
\hline Duration of therapy - mo & & $23(0.4-35.9)$ \\
\hline
\end{tabular}

* Data on time to conversion were available for the 66 patients who completed at least four months of therapy. For all other variables, data were available for all 75 patients. highly resistant tuberculosis, extensive parenchymal damage, and previous exposure to repeated, standardized regimens that probably resulted in the amplification of drug resistance. The percentage with probable cures in our community-based, ambulatory program ( 83 percent) was as high as any reported in a hospital setting to date.

The seminal report on the treatment of severe multidrug-resistant tuberculosis in a referral hospital in the United States documented a favorable response in 65 percent of patients. ${ }^{42}$ In reports from middle-income countries or regions, the percentages responding favorably ranged from 50 percent in Taiwan ${ }^{14}$ to more than 80 percent in Hong Kong, ${ }^{15}$ Korea, ${ }^{16}$ and Turkey. ${ }^{17}$ The only comparisons to date of studies among outpatients are from Florida, in which only 48 percent of patients completed treatment, ${ }^{19}$ and Korea and Peru (a study using the Peruvian National Tuberculosis Program standardized regimen), in which 48 percent were cured. ${ }^{18,20}$

The encouraging outcomes in Lima are proba- 
bly due to several factors, some unique to our study population and others to the treatment program. Although our patients had been sick for longer and had higher-grade resistance than those in other cohorts, they were generally younger, with fewer serious coexisting conditions. Unlike the cohorts in Korea and Florida, which had high default rates, ${ }^{18,19}$ all patients in our cohort received directly observed therapy. Adverse effects, moreover, were carefully managed to ensure completion of treatment: only one patient withdrew from therapy because of adverse events. ${ }^{41}$

Therapy was more aggressive than in other studies; patients were treated with more drugs and at higher doses for longer periods. ${ }^{13,41,43}$ It is likely that this protocol mitigated, to some degree, the effect of high-grade resistance. In other cohorts, such resistance has increased the likelihood of treatment failure. ${ }^{42,44,45}$ Furthermore, the use of individualized regimens permitted patients to receive treatment with maximally effective drug combinations to which the strains had documented in vitro susceptibility, thus reducing the risk of further amplification of resistance. ${ }^{46,47}$ More than 70 percent of the patients with strains resistant to all five firstline drugs had probable cures at the completion of treatment.

Our results suggest that shortening the time to the initiation of appropriate therapy will further improve outcomes and reduce costs in a number of ways. Most important, in a setting with high cure rates with first-line treatment, patients in whom directly observed, short-course regimens have failed and patients thought to have primary multidrugresistant tuberculosis are unlikely to benefit from the standardized retreatment regimens recommended for resource-poor settings. ${ }^{48}$ Additional courses of therapy based on isoniazid and rifampin are likely to lead to increased parenchymal damage and amplified resistance to the other first-line drugs. ${ }^{6}$ In fact, in a preliminary analysis from a larger cohort of patients in Lima, resistance to streptomycin, pyrazinamide, and ethambutol was three times as likely in strains collected from patients who had been treated with two or more previous regimens as in those who had received no treatment or treatment with only one regimen. 49

The treatment of patients with strains resistant to four or five first-line drugs is more difficult and more expensive than the treatment of those whose strains are sensitive to one or more of these agents. We found that patients with strains resistant to pyr-
Table 3. Suspected Causes of Death among Patients Who Died during or after Individualized Treatment.

Cause During Therapy After Completion of Therapy $<4 \mathrm{mo} \quad \geq 4 \mathrm{mo}$ Completed Completed

Respiratory failure

Sepsis (multisystem organ failure)

Relapse or reinfection with multidrug-resistant tuberculosis

Probable narcotic overdose

Unknown
3

5

0

0

1

0

2

1

0

0

1 (43 wk after completion) azinamide and ethambutol were more likely to have poor outcomes. Moreover, the resistance pattern was the greatest determinant of the cost of therapy in this cohort, with costs per patient ranging from $\$ 504$ to $\$ 32,383$. At a mean of $\$ 15,681$ per patient, these costs were low - approximately 10 percent of those for hospitalized patients ${ }^{50,51}$ - but well beyond the reach of most national tuberculosis programs. Advocacy work and pooled procurement have since resulted in dramatic decreases in the costs of second-line antituberculosis drugs. ${ }^{52}$ Now such patients can be treated for approximately half the earlier cost; preserved susceptibility to pyrazinamide and ethambutol further reduces the expense.

The association between signs of severe, protracted disease - elevated resting respiratory rate, bilateral involvement, low body-mass index, and anemia - and poor outcome is not unexpected and further underscores the importance of early referral for appropriate therapy. ${ }^{53-55}$ Aggressive adjuvant interventions (blood transfusion, hyperalimentation, and supplemental oxygen) may be important for reducing mortality among chronically ill patients. Even if these costly therapies prove beneficial, however, referring patients to appropriate therapy before they have manifestations of chronic disease would save both lives and resources. It would also reduce rates of transmission. Inadequately treated patients often remain infectious, transmitting multidrug-resistant strains to household members and health care workers.

The poorer outcomes for women, although not fully explained by the data available for this population, are consistent with the elevated risk of progres- 


\begin{tabular}{|c|c|c|c|c|}
\hline \multirow[t]{2}{*}{ Risk Factor } & \multirow[t]{2}{*}{$\begin{array}{l}\text { Patients with } \\
\text { Poor Outcomes }\end{array}$} & \multicolumn{2}{|c|}{ Univariate Analysis } & \multirow{2}{*}{$\begin{array}{l}\text { Multivariate } \\
\text { Analysis } \\
\text { Adjusted } \\
\text { Hazard Ratio } \\
(95 \% \mathrm{Cl})\end{array}$} \\
\hline & & $\begin{array}{c}\text { Crude } \\
\text { Hazard Ratio } \\
(95 \% \mathrm{Cl})\end{array}$ & $\begin{array}{c}\mathrm{P} \\
\text { Value } \dagger\end{array}$ & \\
\hline \multicolumn{5}{|c|}{ no./total no. } \\
\hline Sex & & $2.14(0.80-5.71)$ & 0.13 & - \\
\hline Female & $12 / 38$ & & & \\
\hline Male & $6 / 37$ & & & \\
\hline Age & & $1.40(0.54-3.65)$ & 0.49 & - \\
\hline$>26.8 \mathrm{yr}$ & $7 / 37$ & & & \\
\hline$\leq 26.8 \mathrm{yr}$ & $11 / 38$ & & & \\
\hline Body-mass index & & $5.13(1.68-15.69) \ddagger$ & 0.004 & $3.23(0.90-11.53) \mathbb{\int}$ \\
\hline Low & $14 / 32$ & & & \\
\hline Normal & $4 / 43$ & & & \\
\hline Hematocrit & & $5.17(2.03-13.17) \dagger$ & $<0.001$ & $4.09(1.35-12.36) \div$ \\
\hline Low & $8 / 12$ & & & \\
\hline Normal & $10 / 63$ & & & \\
\hline Radiographic findings & & $1.77(0.64-4.64)$ & 0.28 & - \\
\hline Bilateral disease and cavitary lesions & $14 / 50$ & & & \\
\hline Bilateral disease only & $4 / 21$ & & & \\
\hline Neither bilateral disease nor cavitary lesions & $0 / 4$ & & & \\
\hline Resting respiratory rate & & $10.32(1.27-84.04) \div$ & 0.03 & - \\
\hline$>26$ breaths $/ \mathrm{min}$ & $1 / 16$ & & & \\
\hline$\leq 26$ breaths $/ \mathrm{min}$ & $7 / 13$ & & & \\
\hline Pyrazinamide and ethambutol in regimen $\|$ & & $0.47(0.19-1.18)$ & 0.11 & $0.30(0.11-0.83) \div \delta$ \\
\hline Neither & $13 / 42$ & & & \\
\hline Either & $5 / 27$ & & & \\
\hline Both & $0 / 6$ & & & \\
\hline Parity** & & $3.87(0.82-18.21)$ & 0.09 & $7.48(1.50-37.34) \div$ \\
\hline 0 live births & $9 / 23$ & & & \\
\hline$\geq 1$ live births & $3 / 15$ & & & \\
\hline denotes confidence interval. Both univariate a & ultivariate analy & es were Cox proportior & nal-hazarc & regression analyses. \\
\hline $\mathrm{P}$ values were derived by the Wald $\chi^{2}$ test. & & & & \\
\hline $\mathrm{P}<0.05$ by the Wald $\chi^{2}$ test. & & & & \\
\hline $\begin{array}{l}\text { The multivariate model included low hematocrit, } \\
\text { ethambutol. }\end{array}$ & $v$ body-mass inde & and the combined pre & dictor for & razinamide and \\
\hline $\begin{array}{l}\text { The resting respiratory rate was not included in } t \\
\text { values. }\end{array}$ & multiple logistic-re & ression models becau & se of the la & ge number of missing \\
\hline $\begin{array}{l}\text { Exclusion of these drugs was predicated on defir } \\
\text { least one confirmation of susceptibility. }\end{array}$ & e evidence of in $v$ & ro resistance. Inclusior & in the reg & nen was based on at \\
\hline *Only women were included. The multivariate mo & vas adjusted for & nemia and low body-r & ass inde & \\
\hline
\end{tabular}

sion from infection to disease, increased mortality, and higher incidence of extrapulmonary disease among women with tuberculosis in many parts of the world. ${ }^{56-58}$ Our finding that young, childless women were less likely to respond to therapy may point to the important role of adult children, who often provided substantial support to their mothers. It is also possible that the long-standing disease afflicting young women in northern Lima was so debilitating as to have precluded reproduction for physiological and social reasons.

Our experience establishes that patients with chronic multidrug-resistant tuberculosis can be treated successfully as outpatients outside referral centers and in a resource-poor country. The DOTSPlus model relies on community health workers supervised by nurses working in close collaboration with the country's successful National Tuberculosis 
Program. By moving treatment into the community, it is possible, without compromising the quality of therapy, to lower costs and reduce the risk of nosocomial spread of multidrug-resistant tuberculosis. ${ }^{59-61}$ During the past two years, we have expanded the DOTS-Plus model to cover much of Lima. The costs of therapy have continued to drop even as control over the distribution of second-line drugs has been enhanced. Successful communitybased therapy for multidrug-resistant tuberculosis
— and potentially for HIV62,63 — provides hope for the tens of millions of patients who are suffering from chronic infectious diseases in settings with limited health infrastructure.

Supported by Thomas J. White, the Massachusetts State Laboratory Institute, a grant (AI 03535, to Dr. Mitnick) from the National Institute of Allergy and Infectious Diseases, Eli Lilly, and the Bill and Melinda Gates Foundation.

We are indebted to the Peruvian team and the Haitian team (led by Dr. Fernet Léandre) for their dedication and skill in caring for the patients, and to Edward Nardell, Rajesh Gupta, Norman Johnson, and Michaele Mikovsky for their comments on the manuscript.

\section{REFERENCES}

1. Pablos-Méndez A, Raviglione MC, Laszlo A, et al. Global surveillance for antituberculosis-drug resistance, 1994-1997. N Engl J Med 1998;338:1641-9. [Erratum, N Engl J Med 1998;339:139.]

2. Espinal MA, Laszlo A, Simonsen L, et al. Global trends in resistance to antituberculosis drugs. N Engl J Med 2001;344:1294-303. 3. Dye C, Williams BG, Espinal MA, Raviglione MC. Erasing the world's slow stain: strategies to beat multidrug-resistan tuberculosis. Science 2002;295:2042-6.

4. Maher D, Chaulet P, Spinaci S, Harries A. Treatment of tuberculosis: guidelines for national programmes. 2nd ed. Geneva: World Health Organization 1997. (WHO TB/97.220.)

5. Espinal MA, Dye C, Raviglione MC Kochi A. Rational 'DOTS plus' for the control of MDR-TB. Int J Tuberc Lung Dis 1999 3:561-3.

6. Farmer PE, Bayona J, Becerra M, et al Poverty, inequality, and drug resistance meeting community needs. In: Proceedings of the International Union against Tuberculosis and Lung Disease North American Region Conference, Chicago, February 27March 2, 1997:88-101.

7. Coninx R, Mathieu C, Debacker M, et al First-line tuberculosis therapy and drugresistant Mycobacterium tuberculosis in prisons. Lancet 1999;353:969-73.

8. García-García ML, Ponce de León A Jiménez-Corona ME, et al. Clinical consequences and transmissibility of drug-resistant tuberculosis in southern Mexico. Arch Intern Med 2000;160:630-6.

9. Primary multidrug-resistant tuberculosis - Ivanovo Oblast, Russia, 1999. MMWR Morb Mortal Wkly Rep 1999;48:661-4.

10. Espinal MA, Kim SJ, Suárez PG, et al. Standard short-course chemotherapy for drug-resistant tuberculosis: treatment outcomes in 6 countries. JAMA 2000;283:253745.

11. TB/HIV: a clinical manual. Geneva: World Health Organization, 1996. (WHO TB/96.200.)

12. Crofton J, Chaulet P, Maher D. Guidelines on the management of drug-resistant tuberculosis. Geneva: World Health Organization, 1997.
13. Hadiarto M, Tjandra YA, Hudoyo A Treatment of multidrug-resistant tuberculosis in Indonesia. Chemotherapy 1996;42 Suppl 3:24-9.

14. Suo J, Yu MC, Lee CN, Chiang CY, Lin TP. Treatment of multidrug-resistant tuberculosis in Taiwan. Chemotherapy 1996;42: Suppl 3:20-3.

15. Yew WW, Chan CK, Chau CH, et al. Outcomes of patients with multidrug-resistant pulmonary tuberculosis treated with ofloxacin/levofloxacin-containing regimens. Chest 2000;117:744-51.

16. Park SK, Kim CT, Song SD. Outcome of chemotherapy in 107 patients with pulmo nary tuberculosis resistant to isoniazid and rifampin. Int J Tuberc Lung Dis 1998;2:87784.

17. Tahaoğlu K, Törün T, Sevim T, et al. The treatment of multidrug-resistant tuberculosis in Turkey. N Engl J Med 2001;345:170-4 18. Kim HJ, Hong YP, Kim SJ, Lew WJ, Lee EG. Ambulatory treatment of multidrugresistant pulmonary tuberculosis patients a a chest clinic. Int J Tuberc Lung Dis 2001;5: 1129-36.

19. Narita M, Alonso P, Lauzardo M, Hollender ES, Pitchenik AE, Ashkin D. Treatment experience of multidrug-resistant tuberculosis in Florida, 1994-1997. Chest 2001;120:343-8.

20. Suarez PG, Floyd K, Portocarrero J, et al. Feasibility and cost-effectiveness of stand ardised second-line drug treatment for chronic tuberculosis patients: a national cohort study in Peru. Lancet 2002;359:1980 9.

21. Davies GR, Pillay M, Sturm AW, Wilkinson D. Emergence of multidrug-resistant tuberculosis in a community-based directly observed treatment programme in rural South Africa. Int J Tuberc Lung Dis 1999;3 799-804.

22. Ridzon R, Kent JH, Valway S, et al. Outbreak of drug-resistant tuberculosis with second-generation transmission in a high school in California. J Pediatr 1997;131: 863-8.

23. Laserson KF, Osorio L, Sheppard JD, et al. Clinical and programmatic mismanagement rather than community outbreak as the cause of chronic, drug-resistant tuber- culosis in Buenaventura, Colombia. Int J Tuberc Lung Dis 2000;4:673-83. 24. Kimerling ME, Kluge $H$, Vezhnina N, et al. Inadequacy of the current WHO re-treatment regimen in a central Siberian prison: treatment failure and MDR-TB. Int J Tuberc Lung Dis 1999;3:451-3.

25. Bastian I, Rigouts L, Van Deun A, Portaels F. Directly observed treatment, shortcourse strategy and multidrug-resistant tuberculosis: are any modifications required? Bull World Health Organ 2000;78:238-51.

26. Scientific Panel of the Working Group on DOTS-Plus for MDR-TB. Guidelines for establishing DOTS-Plus pilot projects for the management of multidrug-resistant tuberculosis (MDR-TB). Geneva: World Health Organization, 2000. (WHO/CDS/TB/ 2000.279.)

27. Laserson KF, Iademarco MF. Profiling drug resistance in immigrants with tuberculosis. Chest 2000;117:623-5.

28. Farmer PE, Kim JY. Community based approaches to the control of multidrug resistant tuberculosis: introducing "DOTSplus." BMJ 1998;317:671-4.

29. Farmer PE, Kim JY, Mitnick C, Timperi R. Responding to outbreaks of MDRTB: introducing "DOTS-Plus." In: Reichman LB, Hershfield ES, eds. Tuberculosis: a comprehensive international approach. 2nd ed. New York: Marcel Dekker, 2000:447-69.

30. Farmer PE, Walton DA, Becerra MC. International tuberculosis control in the 21st century. In: Friedman LN, ed. Tuberculosis: current concepts and treatment. 2nd ed. Boca Raton, Fla.: CRC Press, 2000:47596.

31. Centro Panamericano de Zoonosis. Bacteriología de la tuberculosis. Nota técnica no. 27. Buenos Aires, Argentina: OPS/OMS, 1985.

32. Kent PT, Kubica GP. Public health mycobacteriology: a guide for the level III laboratory. Atlanta: Centers for Disease Control, 1985.

33. Heifets LB. Drug susceptibility testing. Clin Lab Med 1996;16:641-56.

34. Farmer PE, Furin JJ, Shin SS. Managing multidrug-resistant tuberculosis. J Respir Dis 2000;21:53-6.

35. Sweetland A, Acha J, Guerra D. Enhanc- 
ing adherence: the role of group psychotherapy in the treatment of multidrug-resistant tuberculosis in urban Peru. In: Cohen A, Kleinman A, Saraceno BE, eds. The world mental health casebook: social and mental health programs in low-income countries. New York: Kluwer Academic, 2002:51-79.

36. Bender DA, Bender AE. Nutrition: a reference handbook. Oxford, England: Oxford University Press, 1997.

37. Hematologic alterations. In: Isselbacher KJ, Braunwald E, Wilson JD, Martin JB, Fauci AS, Kasper DL, eds. Harrison's principles of internal medicine. 13th ed. Vol. 1. New York: McGraw-Hill, 1994:313-37.

38. Weinberger SE. Principles of pulmonary medicine. 2nd ed. Philadelphia: W.B. Saunders, 1992.

39. Harris EK, Albert A. Survivorship analysis for clinical studies. New York: Marcel Dekker, 1991

40. Clayton D, Hills M. Statistical models in epidemiology. Oxford, England: Oxford University Press, 1993.

41. Furin JJ, Mitnick CD, Shin SS, et al Occurrence of serious adverse effects in patients receiving community-based therapy for multidrug-resistant tuberculosis. Int J Tuberc Lung Dis 2001;5:648-55.

42. Goble $M$, Iseman MD, Madsen LA, Waite D, Ackerson L, Horsburgh CR Jr. Treatment of 171 patients with pulmonary tuberculosis resistant to isoniazid and rifampin. N Engl J Med 1993;328:527-32.

43. Frieden TR, Sherman LF, Maw KL, et al A multi-institutional outbreak of highly drug-resistant tuberculosis: epidemiology and clinical outcomes. JAMA 1996;276: 1229-35.

44. Salomon N, Perlman DC, Friedmann P, Buchstein S, Kreiswirth BN, Mildvan D. Predictors and outcome of multidrug-resistan tuberculosis. Clin Infect Dis 1995;21:124552.
45. Agerton TB, Valway SE, Blinkhorn RJ, et al. Spread of strain W, a highly drug-resistant strain of Mycobacterium tuberculosis, across the United States. Clin Infect Dis 1999;29: 85-92.

46. Management of tuberculosis: a guide for low income countries. 5th ed. Paris International Union against Tuberculosis and Lung Disease, 2000.

47. Portaels F, Rigouts L, Bastian I. Addressing multidrug-resistant tuberculosis in penitentiary hospitals and in the general population of the former Soviet Union. Int J Tuberc Lung Dis 1999;3:582-8.

48. Becerra MC, Freeman J, Bayona J, et al. Using treatment failure under effective directly observed short-course chemotherapy programs to identify patients with multidrug-resistant tuberculosis. Int J Tuberc Lung Dis 2000;4:108-14.

49. Mitnick CD, Mukherjee J, Alcantara F, et al. Time to culture conversion on individualized therapy for MDR-TB: is previous treatment history important? Presented at the Fourth World Congress on TB, Washington, D.C., June 3-5, 2002. abstract.

50. Outbreak of multidrug-resistant tuberculosis - Texas, California, and Pennsylvania. MMWR Morb Mortal Wkly Rep 1990 39:369-72.

51. Mahmoudi A, Iseman MD. Pitfalls in the care of patients with tuberculosis: common errors and their association with the acquisition of drug resistance. JAMA 1993;270 65-8.

52. Gupta R, Kim JY, Espinal MA, et al. Responding to market failures in tuberculosis control. Science 2001;293:1049-51.

53. Turett GS, Telzak EE, Torian LV, et al. Improved outcomes for patients with multidrug-resistant tuberculosis. Clin Infect Dis 1995;21:1238-44.

54. Avendano M, Goldstein RS. Multidrugresistant tuberculosis: long term follow-up of 40 non-HIV-infected patients. Can Respir J 2000;7:383-9.

55. Park MM, Davis AL, Schluger NW, Cohen H, Rom WN. Outcome of MDR-TB patients, 1983-1993: prolonged survival with appropriate therapy. Am J Respir Crit Care Med 1996;153:317-24.

56. Holmes CB, Hausler H, Nunn P. A review of sex differences in the epidemiology of tuberculosis. Int J Tuberc Lung Dis 1998;2:96-104.

57. Olakowski T. Assignment report on a tuberculosis longitudinal survey. Manila, Philippines: World Health Organization Regional Office for South East Asia, 1973.

58. Groth-Petersen E, Knudsen J, Wilbek E. Epidemiological basis of tuberculosis eradication in an advanced country. Bull World Health Organ 1959;21:5-49.

59. Kenyon TA, Ridzon R, Luskin-Hawk R, et al. A nosocomial outbreak of multidrugresistant tuberculosis. Ann Intern Med 1997:127:32-6.

60. Rullán JV, Herrera D, Cano R, et al. Nosocomial transmission of multidrug-resistant Mycobacterium tuberculosis in Spain. Emerg Infect Dis 1996;2:125-9.

61. Sacks LV, Pendle S, Orlovic D, Blumberg L, Constantinou C. A comparison of outbreak- and nonoutbreak-related multidrugresistant tuberculosis among human immunodeficiency virus-infected patients in a South African hospital. Clin Infect Dis 1999; 29:96-101.

62. Farmer P, Leandre F, Mukherjee JS, et al. Community-based approaches to HIV treatment in resource-poor settings. Lancet 2001;358:404-9.

63. Farmer P. The major infectious diseases in the world - to treat or not to treat? $\mathrm{N} \mathrm{Engl}$ J Med 2001;345:208-10.

Copyright $\odot 2003$ Massachusetts Medical Society.

\section{IMAGES IN CLINICAL MEDICIN}

The Journal welcomes consideration of new submissions for Images in Clinical Medicine. Instructions for authors and procedures for submissions can be found on the Journal's Web site at http://www.nejm.org. At the discretion of the editor, images that are accepted for publication may appear in the print version of the Journal, the electronic version, or both. 